\title{
What is asthma-COPD overlap syndrome? Towards a consensus definition from a round table discussion
}

\author{
Don D. Sin ${ }^{1}$, Marc Miravitlles ${ }^{2}$, David M. Mannino ${ }^{3}$, Joan B. Soriano ${ }^{4}$, \\ David Price ${ }^{5,6}$, Bartolome R. Celli ${ }^{7}$, Janice M. Leung ${ }^{1}$, Yasutaka Nakano ${ }^{8}$, \\ Hye Yun Park ${ }^{9}$, Peter A. Wark ${ }^{10}$ and Michael E. Wechsler ${ }^{11}$
}

\begin{abstract}
Affiliations: ${ }^{1}$ Centre for Heart Lung Innovation, St. Paul's Hospital, \& Department of Medicine (Respiratory Division), University of British Columbia, Vancouver, BC, Canada. ${ }^{2}$ Servicio de Neumología, Hospital Universitari Vall d'Hebron, Barcelona, Spain; CIBER de Enfermedades Respiratorias (CIBERES), Spain. ${ }^{3}$ Dept of Preventive Medicine and Environmental Health, University of Kentucky, College of Public Health, Lexington, KY, USA. ${ }^{4}$ Instituto de Investigación Hospital Universitario de la Princesa (IISP), Universidad Autónoma de Madrid, Madrid, Spain. ${ }^{5}$ Centre for Academic Primary Care, The Institute of Applied Health Sciences, University of Aberdeen, Aberdeen, UK. ${ }^{6}$ Research in Real-Life, Cambridge, UK. ${ }^{7}$ Division of Pulmonary and Critical Care Medicine, Brigham and Women's Hospital, Harvard Medical School, Boston, MA, USA. ${ }^{8}$ Dept of Medicine, Division of Respiratory Medicine, Shiga University of Medical Science, Shiga, Japan. ${ }^{9}$ Division of Pulmonary and Critical Care Medicine, Department of Medicine, Samsung Medical Center, Sungkyunkwan University School of Medicine, Seoul, South Korea. ${ }^{10}$ Priority Centre for Healthy Lungs, HMRI University of Newcastle, Newcastle, Australia. ${ }^{11}$ Dept of Medicine, National Jewish Health, Denver, CO, USA.
\end{abstract}

Correspondence: Don D. Sin, St. Paul's Hospital, Vancouver, BC, V6Z Y16. E-mail: don.sinđahli.ubc.ca

ABSTRACT Patients with asthma-chronic obstructive pulmonary disease overlap syndrome (ACOS) have been largely excluded from pivotal therapeutic trials and, as a result, its treatment remains poorly defined and lacking firm evidence. To date, there is no universally accepted definition of ACOS, which has made it difficult to understand its epidemiology or pathophysiology. Despite many uncertainties, there is emerging agreement that some of the key features of ACOS include persistent airflow limitation in symptomatic individuals 40 years of age and older, a well-documented history of asthma in childhood or early adulthood and a significant exposure history to cigarette or biomass smoke. In this perspective, we propose a case definition of ACOS that incorporates these key features in a parsimonious algorithm that may enable clinicians to better diagnose patients with ACOS and most importantly enable researchers to design therapeutic and clinical studies to elucidate its epidemiology and pathophysiology and to ascertain its optimal management strategies.

@ERSpublications

We propose that asthma-COPD overlap syndrome be defined based on three major criteria and one minor criterion http://ow.ly/3rOU304aTNm

Support statement: The round table discussion was funded by Boehringer Ingelheim (BI) Canada. The funder had no input in the contents of the discussions and no role in preparation of the manuscript. Funding information for this article has been deposited with FundRef.

Conflict of interest: Disclosures can be found alongside this article at erj.ersjournals.com

Copyright OERS 2016 


\section{Introduction}

A global expert panel discussion, comprising of specialists and generalists from North America, Western Europe and Asia, was held in Denver (CO, USA) on May 16, 2015, to discuss asthma-chronic obstructive pulmonary disease (COPD) overlap syndrome (ACOS) and to develop a framework to scientifically and clinically advance the field. The experts discussed the current state of knowledge of ACOS and identified critical gaps in knowledge. These discussions were continued through electronic media (e.g. e-mail) until the end of February 2016 and any new relevant data that emerged in 2015-2016 were incorporated into these discussions. It should be noted that, while the group reached an agreement on the most salient features of ACOS through discussion, iteration and electronic communications, there was not uniformity or singularity of opinion. Moreover, we did not use a structured format (e.g. Delphi or nominal group method) to achieve consensus $[1,2]$. Thus, in this paper, we use the word "consensus" synonymously with "agreement", rather than the more technical definition, denoting convergence of opinions to singularity (or uniformity).

\section{The key consensus points of the discussions}

1. For ACOS to move forward as a unique entity, a universally accepted operational definition is urgently required, even if it is not perfect. The panel favoured a definition consisting of major and minor criteria, analogous to the approach for operationally defining rheumatic fever [3].

2. The key features of ACOS, which should be considered in the operational definition, included: 1) persistent airflow limitation on spirometry despite adequate administration of a short-acting bronchodilator in subjects 40 years of age or older; 2) a "significant" history of cigarette smoking or an equivalent lifetime exposure to biomass; and 3) a physician diagnosis of asthma before 40 years of age.

3. While evidence-based treatments on ACOS are scarce, inhaled corticosteroids combined with a long-acting bronchodilator may be reasonable for ACOS patients, especially in those with elevated serum or sputum eosinophils. However, there is sufficient clinical equipoise to initiate clinical trials addressing this issue.

Why is ACOS necessary as a "new" disease entity?

It has been long recognised that features of asthma and COPD may co-exist in patients who present with airflow limitation and symptoms of cough and/or dyspnoea [4]. Based on this observation, in 1961, Professor Orie stated that "bronchitis and asthma may be found in one patient at the same age but as a rule there is a fluent development from bronchitis in youth to a more asthmatic picture in adults, which in turn, develops into bronchitis of elderly patients" [5, 6]. Many years later, Fletcher coined the term the "Dutch Hypothesis" to describe the phenomenon of "asthma" becoming "COPD" [6]. Over the years, the merits of the "Dutch Hypothesis" have been hotly debated, with some arguing that asthma and COPD are unique conditions with separate and distinct pathophysiologies and treatments, while others suggesting a spectrum of disease, consistent with the "Dutch Hypothesis" [7].

In the face of this uncertainty, independent investigators and drug companies have traditionally made great efforts to exclude patients with overlapping features of asthma and COPD from pivotal registration clinical trials. Figures 1 and 2 summarise the inclusion and exclusion criteria of some recent phase III COPD and asthma trials. In almost all large COPD clinical trials, lifetime never smokers or those with a significant past or current history of asthma, allergic rhinitis or atopy (the latter two criteria because of their close association with asthma) have been excluded, though there have been some notable exceptions. In contrast, asthma clinical trials have almost always excluded patients with more than a 5 pack-year smoking history and many have also excluded current smokers. A key enrollment criterion for asthma clinical trials has been either 1) airway hyperresponsiveness or 2) significant bronchodilator reversibility (usually $>12-15 \%$ improvement and/or 200 to $400 \mathrm{~mL}$ increase in forced expiratory volume in $1 \mathrm{~s}$ (FEV1) compared with pre-bronchodilator values). It should be noted, however, that $>60 \%$ of patients with COPD with airflow limitation may also demonstrate airway hyperresponsiveness and/or significant bronchodilator reversibility $[20,21]$, though the mechanism for these features in COPD may be different than those in asthma [22].

Upon inspection of the inclusion and exclusion criteria of asthma and COPD clinical trials, it is apparent that modest smokers ( $<10$ pack-years) with persistent airflow limitation and without a significant bronchodilator response have largely been excluded from both asthma and COPD therapeutic trials. The latter are predominantly women beyond 40 years of age, who may be very symptomatic from their airway disease and have a high burden of disease [23]. In the past, these patients have been called "asthmatics", "asthmatic bronchitics", or "chronic asthmatic bronchitics", though most recently a diagnosis of COPD has been increasingly used [24-27]. Because of the traditional label of asthma in these patients, inhaled corticosteroids (with or without a long acting bronchodilator) are often prescribed and, in some cases, in very high doses, leading to adverse effects. However, supportive data for this approach are lacking. 


\begin{tabular}{|c|c|c|c|c|c|}
\hline & TORCH [8] & UPLIFT [9] & $\begin{array}{l}\text { VogeLmeier } \\
{[10]}\end{array}$ & $\begin{array}{l}\text { VERKINDRE } \\
\text { [11] }\end{array}$ & $\begin{array}{c}\text { TONNEL } \\
\text { [12] }\end{array}$ \\
\hline \multicolumn{6}{|l|}{ Exclusion criteria } \\
\hline \multicolumn{6}{|l|}{$\begin{array}{l}\text { Diagnosis of asthma, } \\
\text { non-COPD respiratory } \\
\text { disorders }\end{array}$} \\
\hline \multicolumn{6}{|l|}{$\begin{array}{l}\text { History of asthma, } \\
\text { allergic rhinitis or atopy }\end{array}$} \\
\hline \multicolumn{6}{|l|}{$\begin{array}{l}\text { Blood eosinophil count } \\
>600 \text { cells } \mu \mathrm{L}^{-1}\end{array}$} \\
\hline \multicolumn{6}{|l|}{ Inclusion criteria } \\
\hline \multicolumn{6}{|l|}{$\begin{array}{l}\text { Current or former } \\
\text { smokers with } \geqslant 10 \text { pack- } \\
\text { years }\end{array}$} \\
\hline \multicolumn{6}{|l|}{$\begin{array}{l}\text { Diagnosis of COPD } \\
\text { with pre-BD FEV } 1 \\
\leqslant 60 \% \text { predicted }\end{array}$} \\
\hline \multicolumn{6}{|l|}{$\begin{array}{l}\text { Post-BD }(400 \mu \mathrm{g} \\
\text { albuterol) FEV } 1 \\
\text { increased by }<10 \%\end{array}$} \\
\hline \multicolumn{6}{|l|}{$\mathrm{FEV}_{1} / \mathrm{FVC} \leqslant 70 \%$} \\
\hline \multicolumn{6}{|l|}{$\begin{array}{l}\text { Post-BD FEV } 1<70 \% \\
\text { predicted }\end{array}$} \\
\hline $\begin{array}{l}\text { Residual volume } \\
>125 \% \text { predicted }\end{array}$ & & & & & \\
\hline
\end{tabular}

FIGURE 1 Inclusion and exclusion criteria of select chronic obstructive pulmonary disease (COPD) therapeutic trials. BD: bronchodilator; FEV1: forced expiratory volume in $1 \mathrm{~s}$; FVC: forced vital capacity.

Similarly, smokers with COPD who have had a prior or current history of asthma have also been largely excluded from pivotal therapeutic trials. Thus, while the use of inhaled corticosteroids is generally discouraged in patients with COPD, it is unclear whether patients with coexisting asthmatic features may benefit from a steroid-containing therapeutic regimen [28]. Indeed, this may explain why, in many countries around the world, inhaled steroid-containing inhalers are the most commonly prescribed medications in clinical practice for patients with COPD [29]. With the increasing concern about the cost and the potential adverse effects of inhaled corticosteroids in COPD, there is a pressing need to determine the role of inhaled corticosteroids in these patients.

Although the exact figures are hard to obtain and extremely variable (owing to major differences in the case definition of ACOS used across the studies), a recent report estimates that approximately $15 \%$ of adult patients with persistent airflow limitation may have significant overlap of COPD and asthma [30] and thus may have been excluded from therapeutic trials. Recent reviews have noted that ACOS is unlikely to be a single disease entity and is likely to be a collection of "diseases" with many different clinical phenotypes (e.g. presence of comorbidities), inflammatory biosignatures (e.g. T-helper (Th) type 2 versus Th1 inflammatory signatures in the airways) and disease pathogenesis [31, 32]. In view of this reality, some have suggested that the term "syndrome" be dropped (since syndrome implies a common pathogenesis) [33], while others have recommended that we move beyond diagnostic labels (which are often inaccurate and misleading) to focus on disease phenotypes and endotypes as a precondition for precision medicine $[34,35]$. Others have advocated a major focus on "treatable traits" to promote optimal management of COPD patients with a variety of features (e.g. co-morbidities) that are modifiable with pharmacological and non-pharmacological interventions [36]. While these are reasonable tenets, we believe that before we entertain major changes in the nomenclature of disease entities, it is important to generate high-quality data to support any modifications that may occur. Moreover, it is important to note that these concepts are not necessarily contradictory and may even be complementary. It is possible (and perhaps desirable) to pursue a better understanding of ACOS, while at the same time providing good patient care by optimally treating the "treatable traits". 


\begin{tabular}{|c|c|c|c|c|c|c|c|}
\hline & $\begin{array}{l}\text { Stempel } \\
{[13]}\end{array}$ & $\begin{array}{c}\text { KERSTJENS } \\
{[14]}\end{array}$ & $\begin{array}{l}\text { Peters } \\
{[15]}\end{array}$ & $\begin{array}{c}\text { AARONSON } \\
{[16]}\end{array}$ & $\begin{array}{l}\text { BusSE } \\
{[17]}\end{array}$ & $\begin{array}{c}\text { HAAHTELA } \\
{[18]}\end{array}$ & $\begin{array}{l}\text { Kuo } \\
{[19]}\end{array}$ \\
\hline \multicolumn{8}{|l|}{ Exclusion criteria } \\
\hline \multicolumn{8}{|l|}{$\begin{array}{l}\text { Ever told by physician that } \\
\text { they had chronic bronchitis, } \\
\text { emphysema or COPD }\end{array}$} \\
\hline \multicolumn{8}{|l|}{ Current smoker } \\
\hline \multicolumn{8}{|l|}{ Smoking >5 pack-years } \\
\hline \multicolumn{8}{|l|}{ Inclusion criteria } \\
\hline \multicolumn{8}{|l|}{$\begin{array}{l}\text { Clinical diagnosis of } \\
\text { asthma } \geqslant 1 \text { year prior to } \\
\text { randomisation }\end{array}$} \\
\hline \multicolumn{8}{|l|}{ PEF $\geqslant 50 \%$ predicted } \\
\hline \multicolumn{8}{|l|}{ FEV $1>40 \%$ predicted } \\
\hline \multicolumn{8}{|l|}{$\begin{array}{l}\text { Confirmed asthma diagnosis } \\
\text { via either 1) } 12 \% \text { post-BD } \\
\text { reversibility or } 2 \text { ) PC20 } \\
<8 \mathrm{mg} \cdot \mathrm{mL}^{-1} \text { not on ICS or } \\
<16 \mathrm{mg} \cdot \mathrm{mL}^{-1} \text { on ICS }\end{array}$} \\
\hline \multicolumn{8}{|l|}{$\begin{array}{l}\text { Lifelong nonsmoker } \\
\text { or smoking history of } \\
<10 \text { pack-years and } \\
\text { nonsmoker at enrolment }\end{array}$} \\
\hline \multicolumn{8}{|l|}{$\begin{array}{l}\geqslant 15 \% \mathrm{FEV} 1 \text { revsersibility } \\
\text { with inhaled } \beta_{2} \text { agonist }\end{array}$} \\
\hline \multicolumn{8}{|l|}{$\begin{array}{l}\geqslant 15 \% \text { FEV } 1 \text { decrease } \\
\text { following an exercise test }\end{array}$} \\
\hline \multicolumn{8}{|l|}{$\begin{array}{l}\text { Histamine responsiveness } \\
<32 \mathrm{mg} \cdot \mathrm{mL}^{-1}\end{array}$} \\
\hline Normal chest radiograph & & & & & & & \\
\hline
\end{tabular}

Included in trials

Not included in trials

FIGURE 2 Inclusion and exclusion criteria in select asthma trials. COPD: chronic obstructive pulmonary disease; PEF: peak expiratory flow; FEV1: forced expiratory volume in $1 \mathrm{~s}$; BD: bronchodilator; PC20: provocative concentration causing a $20 \%$ fall in FEV1; ICS: inhaled corticosteroid.

\section{How has ACOS been defined in clinical studies?}

It should be noted that the operational definition of ACOS has varied across studies [37]. The Global Initiative for Chronic Obstructive Lung Disease (GOLD)/ Global Initiative for Asthma (GINA) document on ACOS, for instance, advocates a "tick-box" approach to ACOS diagnosis consisting of certain clinical characteristics (e.g. doctor diagnosis of asthma and exposure to noxious stimuli) and spirometric features (e.g. a "significant" bronchodilator response) [38]. However, it is unclear how many (or which) "tick" boxes need to be checked off before ACOS can be diagnosed. Others have suggested, in addition to a combined history of asthma and COPD, objective measures such as a "large" bronchodilator response on FEV1, serum IgE levels or eosinophil counts on sputum [39, 40].

Although there is heterogeneity, most guidelines and publications largely agree on the following components or traits of ACOS: 1) presence of persistent airflow limitation in adults 40 years of age and older; 2) a significant smoking or biomass exposure history; and 3) a history of atopy or asthma [40].

\section{Persistent airflow limitation}

GOLD has defined persistent airflow limitation based on a fixed cutoff of post-bronchodilator FEV1/forced vital capacity $(\mathrm{FVC})<0.70$ [41]. While this is most commonly used due to its simplicity, there is a compelling argument for using age-adjusted cutoff values. The more controversial aspect of ACOS is the bronchodilator response. The American Thoracic Society (ATS) criterion for a significant bronchodilator 
response is an FEV1 or FVC improvement of $\geqslant 200 \mathrm{~mL}$ or $12 \%$ from baseline values [42]. However, this threshold cannot reasonably separate asthma from COPD. Indeed, one study reported a receiver operating characteristics area under the curve (ROC-AUC) value of 0.57 regardless of whether FEV1 or FVC thresholds were used [43]. To improve the diagnostic performance, the Spanish Society of Pulmonology and Thoracic Surgery (SEPAR) has recommended the use of $15 \%$ and $400 \mathrm{~mL}$ as the cutoff for patients with only one spirometric measurement or the traditional $12 \%$ and $200 \mathrm{~mL}$ cutoff for those with multiple measurements [38]. Similarly, the GOLD/GINA document recommends the use of $15 \%$ and a $400 \mathrm{~mL}$ cutoff for ACOS. However, none of these cutoff values has been shown to have excellent performance characteristics in clearly separating asthma and COPD. Moreover, bronchodilator response (BDR) in general is highly variable over time in COPD [44]. Thus, the usefulness of BDR for diagnosing ACOS is uncertain.

\section{Recommendations on the spirometric criteria for ACOS}

Persistent airflow limitation should be a major criterion for ACOS. Thus, it is imperative to perform preand post-bronchodilator spirometry according to ATS/European Respiratory Society (ERS) recommendations in all patients. An age-adjusted cutoff value for FEV1/FVC is preferred; however, in some jurisdictions where normative values are not widely available, fixed ratio cutoffs can be used. It is preferred that this criterion be met with multiple (and not just a single) spirometric measurements over time.

While significant BDRs have been traditionally linked with asthma, it is now well known that some patients with COPD demonstrate significant improvements in FEV1 following bronchodilators. However, in general, the BDRs tend to be small in magnitude and quite variable in patients with COPD [45], unlike in asthma where BDRs are generally larger and more robust. The committee believes that given the uncertainty of BDR thresholds in separating patients with COPD versus those with asthma, it should not be a major criterion for ACOS with the following exception.

In individuals who do not have a physician diagnosis of asthma before the age of 40 years, BDR may be used as a major diagnostic criterion of ACOS if the subject demonstrates a very large BDR, defined as $>400 \mathrm{~mL}$ [46] increase in baseline FEV1 following 400 ug of albuterol/salbutamol (or equivalent). This exception is being permitted as some individuals may manifest their first symptoms of asthma at age 40 years or older [47].

\section{Tobacco smoking and biomass exposure}

Although the pathogenesis of COPD is not entirely known, it is well established that in most high-income countries, cigarette smoking is the leading environmental risk factor accounting for $60-80 \%$ of the cases $[48,49]$. Despite the worldwide efforts to curb the use of cigarettes, smoking is common in most countries [50]. Even in the USA and Canada, where anti-smoking policies and legislation are very stringent, the prevalence of smoking is $15-20 \%$ among adults 20 years of age and older. Counter-intuitively, in most countries, the prevalence of smoking in adult asthmatics is similar to the general population without asthma [51]. Epidemiological studies suggest that asthma and cigarette smoking synergistically accelerate the rate of decline in lung function in adults [52]. Female smokers in particular may be at increased risk of COPD [48]. Thus in women, COPD may develop with only a modest number of pack-years of smoking and the traditional cut-offs of 10 pack-years may be too stringent. In developing countries, cigarette smoking is also an important driver of COPD; however, biomass exposure may also play a significant role in the pathogenesis of COPD, especially among women [48, 53]. Indeed, in developing countries, the population-attributable risk of COPD for indoor air pollution, mostly in the form of biomass smoke, is $26 \%$ (similar to that imposed by tobacco smoking, also at 26\%) [49]. Interestingly, biomass-related COPD may have a different phenotype (airway predominant) and disease pathogenesis compared with tobacco-related COPD (which is a variable mix of emphysema and airway disease) [54, 55]. Despite the growing burden of biomass-related COPD (non-tobacco related COPD), no large-scale therapeutic trials have been conducted in this population of patients. Thus, evidence-based therapeutic choices for these patients are completely lacking.

\section{Recommendation on the environmental exposure for ACOS}

Current or past cigarette smoking should be a major criterion for ACOS. However, there is uncertainty on the exact pack-year cutoff that is appropriate for ACOS. Until more data are available, a reasonable cutoff is $\geqslant 10$ pack-years for smokers in countries where biomass exposure is not a major contributor to airflow limitation (e.g. North America and Western Europe).

It should also be noted that in some parts of the world (e.g. Africa, Southeast Asia and China), indoor and outdoor pollution play a key pathogenic role in asthma and COPD in non-smokers or intermittent (light) smokers. However, there is no universally accepted method to quantitate these exposures. Thus, in these jurisdictions, the committee recommends that this criterion may be fulfilled in non-smokers or smokers with $<10$ pack-years, who have "equivalent" biomass or outdoor air pollution exposure as deemed by their primary healthcare provider. 
History of asthma or atopy before age 40 years

Childhood asthma is common, affecting $\sim 10 \%$ of the population in industrialised countries. However, many children $(\sim 80 \%)$ "outgrow" their asthma when they reach adulthood [56]. Clinical features that are predictive of remission include lack of sensitisation and allergen exposure, higher baseline FEV1 and reduced airway hyperresponsiveness at the first assessment [57]. Asthma can also develop in "adulthood" (arbitrarily defined as asthma onset after 12 years of age [58]). Adult-onset asthma often occurs in non-atopic females with a history of rhinitis [59]. It is often fraught with a large burden of symptoms [60] and is associated with persistent airflow limitation and accelerated decline in lung function [60, 61]. It should be noted, however, that while both rhinitis (especially allergic rhinitis) and atopy are significant risk factors for asthma, elevating the risk of asthma by 1.67- and 3.90-fold, respectively [62], fewer than $50 \%$ of the adults with these features (followed for more than 8 years) develop asthma [62]. Interestingly, a recent study of ACOS suggested that COPD patients with a history of asthma may have different clinical features compared with COPD patients without a history of asthma including a significant BDR, higher eosinophil counts in the blood, and elevated total serum IgE concentrations [63].

Recommendation on history of asthma or atopy before age 40 years

A history of childhood or adult-onset asthma should be a major criterion for ACOS. As the prevalence of COPD increases after age 40 years, an age cutoff of 40 years is reasonable to improve the accuracy of the diagnosis.

However, the committee also recognised that asthma can develop in individuals 40 years of age and older. Although COPD patients can demonstrate a significant BDR, it is generally less than $400 \mathrm{~mL}$ [45]. Thus, in those without a documented history of asthma before 40 years of age, this criterion may be met by demonstrating a BDR of $>400 \mathrm{~mL}$ [46] (please see previous discussion on this).

While many patients with asthma have a history of atopy and/or rhinitis, a substantial proportion of adults with atopy and rhinitis do not have or develop asthma [62]. Thus, a history of atopy and rhinitis should not be a major criterion for ACOS.

\section{Blood or sputum eosinophil count and other biomarkers}

In one study, patients with established COPD, who also had a history of asthma or "asthmatic" symptoms (episodic breathlessness, wheezing, cough and chest tightness worsening at night or in the early morning) [64] had on average a two-fold increase in serum IgE levels and peripheral eosinophil count and a six-fold increase in sputum eosinophils (as a \% of total cell count). Interestingly, the COPD patients with asthma, in that study, were more likely to be responsive to inhaled corticosteroids than COPD patients without asthma [64]. Other studies have evaluated the potential usefulness of fractional exhaled nitric oxide (FeNO) and parameters on computed tomography (CT) (e.g. airway wall thickness) to distinguish ACOS from COPD [65]. While these features are useful for research purposes, clinical application has been more challenging owing to, in certain cases, poor standardisation of measurements across centres (e.g. sputum eosinophilia and CT assessments) and lack of clinically defined thresholds to define ACOS. For example, using the upper limit of normative values, approximately 1 in 3 patients with COPD has elevated serum IgE levels $\left(>100 \mathrm{IU} \cdot \mathrm{mL}^{-1}\right)$ [65]; however, it is not entirely clear whether this threshold has any clinical relevance for patients with COPD. Measurement of blood eosinophils, unlike sputum eosinophil counts, is a well-standardised and reproducible test in most clinical laboratories. Although, on average, COPD patients with asthmatic features have elevated peripheral eosinophils, there is little agreement on what constitutes the most appropriate cutoff values. Some have suggested a cutoff of $5 \%$ [30], while others have advocated a $2 \%$ cutoff [66] and still others have suggested using an absolute cell count cutoff (e.g. 300 cells.uL $\left.L^{-1}\right)$ [67] with no consensus on what the absolute threshold should be. Similar problems plague measurements of FeNO. There is no well-established cutoff value that defines an "asthmatic" phenotype among smokers with airflow limitation. Some have suggested a cutoff value of 35 parts per billion (ppb) [65], while others have recommended a $50 \mathrm{ppb}$ threshold [38]. Given the paucity of data on FeNO in ACOS, a firm recommendation is not possible.

\section{Recommendation on biomarkers of asthma}

There is a pressing need for an objective biomarker of ACOS; however, to date, there is no consensus on what that biomarker should be. The most promising is peripheral eosinophil count owing to the ease of measurement and the standardisation of the assay that enables within and across patient and centre comparisons. It may also relate to important clinical outcomes such as risk of exacerbations [68] and therapeutic responsiveness to inhaled corticosteroids [69]. However, currently, there is no agreement on what constitutes the optimal cutoff value for defining ACOS. The most commonly reported value in the literature is $2 \%[66,69-71]$; however, there have been many other cutoff values that have been reported [72]. The committee generally felt that the $2 \%$ threshold lacked sufficient specificity to diagnose eosinophilic airway inflammation [73]. Until more evidence is available, the committee endorses a higher threshold of blood 
eosinophils $\left(\right.$ e.g. $\left.\geqslant 300 \cdot \mathrm{uL}^{-1}\right)$ to increase the specificity of the biomarker to diagnose eosinophilic airway inflammation as a minor criterion for ACOS.

The other biomarkers discussed in this section lack sufficient strength of evidence for consideration in either the major or minor criterion for ACOS. Serum IgE titres are the most promising among this group owing to its availability and standardisation. However, the cutoff values have not been well defined and as such serum IgE measurements cannot be recommended at this time for inclusion in the ACOS definition.

\section{Responsiveness to inhaled corticosteroids}

There is a general feeling that patients with ACOS compared with patients with COPD are more responsive to inhaled corticosteroids. However, strong evidence is not available to support this notion. In one study, PARK et al. [74] evaluated FEV1 improvement after 3 months of treatment with a fixed-dose inhaled corticosteroid/long-acting $\beta_{2}$ combination (ICS/LABA). They found that patients with "ACOS" features (defined as COPD plus elevated peripheral eosinophils) were twice as likely than patients with COPD to have a significant therapeutic response (defined as a $\geqslant 12 \%$ and $\geqslant 200 \mathrm{~mL}$ improvement in FEV 1 above baseline at 3 months) to ICS/LABA. These results require validation and refinement before they can be adopted into clinical practice for patients with ACOS. For instance, it is not entirely clear that a 3 month improvement in FEV1 with ICS/LABA will translate into improvements in patient-oriented or long-term outcomes and, in future studies, it may be more appropriate to evaluate ICS alone (without LABA) to clearly understand the impact of ICS therapy on ACOS patients.

\section{Recommendation on ICS responsiveness in ACOS}

Given that ICS is highly effective in most patients with asthma [75], it is tempting to believe that patients with ACOS would experience benefits from ICS. However, there are very few studies, if any, that have validated this notion. Until a consensus can be reached on the definition of ACOS, it may not be possible to conduct trials to address this critical question. ICS-responsiveness by itself cannot be included in the definition of ACOS as it would constitute a "self-fulfilling" prophecy. Thus, the committee does not endorse its inclusion in the ACOS definition either as a major or minor criterion.

\section{Recommendations on a case definition of ACOS}

Table 1 summarises the major and minor criteria that the committee recommends be used in the diagnosis of ACOS. The committee believes that patients who meet all three major criteria and at least one minor criterion be considered for the diagnosis of ACOS.

The committee recognises that this is an arbitrary definition and one that requires careful validation. Accordingly, these criteria are dynamic and with the addition of new data, modifications may be required.

Notwithstanding the limitation of this approach, for the field to move forward, a consensus definition, even an imperfect one, is urgently required. Without such a case definition, it is impossible to collect (let alone interpret) data on its epidemiology, clinical course or therapeutic responsiveness. This lack of consensus, for instance, may explain the widely divergent data on the prevalence of ACOS, which ranges between $11 \%$ to $56 \%$ among patients previously diagnosed with COPD [35], 13\% to 61\% among patients previously diagnosed with asthma [76] and $\sim 2 \%$ in the general population over 40 years of age [77]. It may also explain why in some studies, ACOS has been associated with more female patients [78, 79], while in others with more male patients $[30,80]$. ACOS has been associated with increased risk of poor quality

TABLE 1 Criteria for diagnosis of asthma-chronic obstructive pulmonary disease overlap syndrome

\begin{tabular}{|c|c|}
\hline Major & Minor \\
\hline $\begin{array}{l}\text { 3. Documented history of asthma before } 40 \text { years of age } \\
\text { OR } \\
\text { BDR of }>400 \mathrm{~mL} \text { in } F E V_{1}\end{array}$ & 3. Peripheral blood eosinophil count of $\geqslant 300$ cells $\cdot u^{-1}$ \\
\hline
\end{tabular}


of life and hospitalisations [81, 82], though paradoxically with reduced rates of lung function decline compared with COPD alone [81]. Until a case definition is determined, these epidemiological and clinical data will be hard to interpret and across study comparisons will be impeded.

\section{Future directions of ACOS: unresolved issues that require urgent attention}

As noted previously, a consensus definition is urgently needed and the first critical enabling step in understanding the clinical context of this entity, measuring the size of the problem by reanalysing both population data and unbiased clinical series of respiratory patients [83], and designing therapeutic and biomarker trials.

Once a definition is established, large longitudinal (non-interventional) studies, or retrospective observational studies are required to understand the clinical and natural history of this entity.

There is also a pressing need to understand the molecular mechanisms of ACOS and its related phenotypes. A recent study suggests that patients with COPD who have clinical features of asthma have an enriched bio-signature of Th2 processes in the airways similar to what is found in the "typical" asthmatic airway (and in contrast to Th1 bias in the "typical" COPD airway) [84]. Another study suggests that there may be different genetic drivers in ACOS than in typical COPD or in asthma [85]. Large and more robust longitudinal data are required to validate these early findings and to discover novel molecular pathways involved in ACOS.

There is also an urgent need to understand the role of inhaled corticosteroids in ACOS. It is widely presumed (but not proven) that patients with ACOS will derive therapeutic benefits from ICS [86]. However, prospective clinical trials are required to validate (or refute) this notion and establish the cost-effectiveness of this approach.

There is also a pressing need to develop easily accessible biomarkers of ACOS. Reliance on a patient's history of "asthma" may be unreliable, leading to misclassification bias. BDR threshold of $400 \mathrm{~mL}$ in FEV1, while intuitive, lacks solid data supporting its use in ACOS. Blood eosinophil counts and serum IgE concentrations are promising but require additional validation before their clinical use can be advocated.

ACOS may not be a single entity. There may be different endotypes within ACOS. For example, it is not certain whether asthmatics who develop fixed airflow limitation related to ageing and/or environmental exposure (smoking or biomass) will have the same molecular drivers, therapeutic responsiveness and prognosis as patients with COPD who have certain "asthmatic" features. Additional work will be needed to elucidate endotypes of ACOS.

\section{Acknowledgements}

The authors wish to thank Karen Bell, who performed a literature review on consensus methods and carefully proofread the manuscript and Lijing Guo, who helped organise the round table meeting.

All of the authors played an active role in the discussions and development of this manuscript. D.D. Sin is the guarantor of the manuscript.

\section{References}

1 Gallagher M, Hares T, Spencer J, et al. The nominal group technique: a research tool for general practice? Fam Pract 1993; 10: 76-81.

2 Everett A. Piercing the veil of the future. A review of the Delphi method of research. Prof Nurse 1993; 9: 181-185.

3 Jones Criteria (modified) for guidance in the diagnosis of rheumatic fever; report of the Committee on Standards and Criteria for programs of care. Circulation 1956; 13: 617-620.

4 Ciba Guest Symposium. Terminology, definitions, and classification of chronic pulmonary emphysema and related conditions. Thorax 1959; 286-299.

5 Orie NG. [The relationship between asthma and chronic obstructive and restrictive pulmonary diseases; lessons from the past century]. Ned Tijdschr Geneeskd 2002; 146: 1504-1508.

6 Postma DS, Weiss ST, van den Berge M, et al. Revisiting the Dutch hypothesis. J Allergy Clin Immunol 2015; 136: 521-529.

7 Tam A, Sin DD. Pathobiologic mechanisms of chronic obstructive pulmonary disease. Med Clin North Am 2012; 96: 681-698.

8 Calverley PM, Anderson JA, Celli B, et al. Salmeterol and fluticasone propionate and survival in chronic obstructive pulmonary disease. N Engl J Med 2007; 356: 775-789.

9 Tashkin DP, Celli B, Senn S, et al. A 4-year trial of tiotropium in chronic obstructive pulmonary disease. $N$ Engl J Med 2008; 359: 1543-1554.

10 Vogelmeier C, Hederer B, Glaab T, et al. Tiotropium versus salmeterol for the prevention of exacerbations of COPD. N Engl J Med 2011; 364: 1093-1103.

11 Verkindre C, Bart F, Aguilaniu B, et al. The effect of tiotropium on hyperinflation and exercise capacity in chronic obstructive pulmonary disease. Respiration 2006; 73: 420-427.

12 Tonnel AB, Perez T, Grosbois JM, et al. Effect of tiotropium on health-related quality of life as a primary efficacy endpoint in COPD. Int J Chron Obstruct Pulmon Dis 2008; 3: 301-310.

13 Stempel DA, Raphiou IH, Kram KM, et al. Serious asthma events with fluticasone plus salmeterol versus fluticasone alone. N Engl J Med 2016; 374: 1833-1830. 
14 Kerstjens HA, Engel M, Dahl R, et al. Tiotropium in asthma poorly controlled with standard combination therapy. N Engl J Med 2012; 367: 1198-1207.

15 Peters SP, Kunselman SJ, Icitovic N, et al. Tiotropium bromide step-up therapy for adults with uncontrolled asthma. N Engl J Med 2010; 363: 1715-1726.

16 Aaronson D, Kaiser H, Dockhorn R, et al. Effects of budesonide by means of the Turbuhaler on the hypothalmic-pituitary-adrenal axis in asthmatic subjects: a dose-response study. J Allergy Clin Immunol 1998; 101: 312-319.

17 Busse WW, Chervinsky P, Condemi J, et al. Budesonide delivered by Turbuhaler is effective in a dose-dependent fashion when used in the treatment of adult patients with chronic asthma. J Allergy Clin Immunol 1998; 101: 457-463.

18 Haahtela $\mathrm{T}$, Jarvinen $\mathrm{M}$, Kava $\mathrm{T}$, et al. Effects of reducing or discontinuing inhaled budesonide in patients with mild asthma. N Engl J Med 1994; 331: 700-705.

19 Kuo HP, Yu TR, Yu CT. Hypodense eosinophil number relates to clinical severity, airway hyperresponsiveness and response to inhaled corticosteroids in asthmatic subjects. Eur Respir J 1994; 7: 1452-1459.

20 Hanania NA, Sharafkhaneh A, Celli B, et al. Acute bronchodilator responsiveness and health outcomes in COPD patients in the UPLIFT trial. Respir Res 2011; 12: 6.

21 Tashkin DP, Altose MD, Bleecker ER, et al. The lung health study: airway responsiveness to inhaled methacholine in smokers with mild to moderate airflow limitation. The Lung Health Study Research Group. Am Rev Respir Dis 1992; 145: 301-310.

22 Grootendorst DC, Rabe KF. Mechanisms of bronchial hyperreactivity in asthma and chronic obstructive pulmonary disease. Proc Am Thorac Soc 2004; 1: 77-87.

23 de Carvalho-Pinto RM, Cukier A, Angelini L, et al. Clinical characteristics and possible phenotypes of an adult severe asthma population. Respir Med 2012; 106: 47-56.

24 Watson L, Vestbo J, Postma DS, et al. Gender differences in the management and experience of chronic obstructive pulmonary disease. Respir Med 2004; 98: 1207-1213.

25 Dales RE, Mehdizadeh A, Aaron SD, et al. Sex differences in the clinical presentation and management of airflow obstruction. Eur Respir J 2006; 28: 319-322.

26 Chapman KR, Tashkin DP, Pye DJ. Gender bias in the diagnosis of COPD. Chest 2001; 119: 1691-1695.

27 Lamprecht B, McBurnie MA, Vollmer WM, et al. COPD in never smokers: results from the population-based burden of obstructive lung disease study. Chest 2011; 139: 752-763.

28 Lapperre TS, Snoeck-Stroband JB, Gosman MM, et al. Effect of fluticasone with and without salmeterol on pulmonary outcomes in chronic obstructive pulmonary disease: a randomized trial. Ann Intern Med 2009; 151: 517-527.

29 White $\mathrm{P}$, Thornton $\mathrm{H}$, Pinnock $\mathrm{H}$, et al. Overtreatment of COPD with inhaled corticosteroids: implications for safety and costs: cross-sectional observational study. PLoS One 2013; 8: e75221.

30 Cosio BG, Soriano JB, Lopez-Campos JL, et al. Defining the asthma-COPD overlap syndrome in a COPD cohort. Chest 2016; 149: 45-52.

31 Tho NV, Park HY, Nakano Y. Asthma-COPD overlap syndrome (ACOS): a diagnostic challenge. Respirology 2016; 21: 410-418.

32 Postma DS, Rabe KF. The asthma-COPD overlap syndrome. N Engl J Med 2015; 373: 1241-1249.

33 Barnes PJ. Asthma-COPD overlap. Chest 2016; 149: 7-8.

34 Pavord I, Bush A. Two Lovely Black Eyes; Oh, what a surprise! Thorax 2015; 70: 609-610.

35 Vanfleteren LE, Kocks JW, Stone IS, et al. Moving from the Oslerian paradigm to the post-genomic era: are asthma and COPD outdated terms? Thorax 2014; 69: 72-79.

36 Agusti A, Bel E, Thomas M, et al. Treatable traits: toward precision medicine of chronic airway diseases. Eur Respir J 2016; 47: 410-419.

37 Alshabanat A, Zafari Z, Albanyan O, et al. Asthma and COPD overlap syndrome (ACOS): a systematic review and meta analysis. PLoS One 2015; 10: e0136065.

38 Global Strategy for Asthma Management and the Prevention and the Global Strategy for the Diagnosis, Management and Prevention of Chronic Obstructive Pulmonary Disease. Diagnosis of Diseases of Chronic Airflow Limitation: Asthma COPD and Asthma-COPD Overlap Syndrome (ACOS). 2015. Available from www. goldcopd.org/uploads/users/files/AsthmaCOPDOverlap.pdf Date last accessed: May 28, 2016.

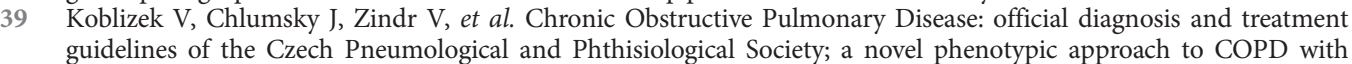
patient-oriented care. Biomed Pap Med Fac Univ Palacky Olomouc Czechoslov 2013; 157: 189-201.

40 Soler-Cataluna JJ, Cosio B, Izquierdo JL, et al. Consensus document on the overlap phenotype COPD-asthma in COPD. Arch Bronconeumol 2012; 48: 331-337.

41 Vestbo J, Hurd SS, Agusti AG, et al. Global strategy for the diagnosis, management, and prevention of chronic obstructive pulmonary disease: GOLD executive summary. Am J Respir Crit Care Med 2013; 187: 347-365.

42 Standardization of Spirometry, 1994 Update. American Thoracic Society. Am J Respir Crit Care Med 1995; 152: $1107-1136$

43 Gjevre JA, Hurst TS, Taylor-Gjevre RM, et al. The American Thoracic Society's spirometric criteria alone is inadequate in asthma diagnosis. Can Respir J 2006; 13: 433-437.

44 Calverley PM, Burge PS, Spencer S, et al. Bronchodilator reversibility testing in chronic obstructive pulmonary disease. Thorax 2003; 58: 659-664.

45 Calverley PM, Albert P, Walker PP. Bronchodilator reversibility in chronic obstructive pulmonary disease: use and limitations. Lancet Respir Med 2013; 1: 564-573.

46 National Institute for Health and Care Excellence (NICE). Diagnosing and assessing COPD. Available from http://pathways.nice.org.uk/pathways/chronic-obstructive-pulmonary-disease\#path=view\%3A/pathways/chronicobstructive-pulmonary-disease/diagnosing-and-assessing-copd.xml\&content=view-node\%3Anodesdifferentiating-between-copd-and-asthma Date last accessed: May 26, 2016.

47 Gibson PG, McDonald VM, Marks GB. Asthma in older adults. Lancet 2010; 376: 803-813.

48 Eisner MD, Anthonisen N, Coultas D, et al. An official American Thoracic Society public policy statement: Novel risk factors and the global burden of chronic obstructive pulmonary disease. Am J Respir Crit Care Med 2010; 182: 693-718.

49 Ezzati M, Hoorn SV, Rodgers A, et al. Estimates of global and regional potential health gains from reducing multiple major risk factors. Lancet 2003; 362: 271-280.

50 The Tobacco Atlas. Available from www.tobaccoatlas.org/ Date last accessed: May 26, 2016. 
51 Rabe KF, Adachi M, Lai CK, et al. Worldwide severity and control of asthma in children and adults: the global asthma insights and reality surveys. J Allergy Clin immunol 2004; 114: 40-47.

52 James AL, Palmer LJ, Kicic E, et al. Decline in lung function in the Busselton Health Study: the effects of asthma and cigarette smoking. Am J Respir Crit Care Med 2005; 171: 109-114.

53 Pinkerton KE, Harbaugh M, Han MK, et al. Women and lung disease. Sex differences and global health disparities. Am J Respir Crit Care Med 2015; 192: 11-16.

54 Camp PG, Ramirez-Venegas A, Sansores RH, et al. COPD phenotypes in biomass smoke- versus tobacco smoke-exposed Mexican women. Eur Respir J 2014; 43: 725-734.

55 King MS, Eisenberg R, Newman JH, et al. Constrictive bronchiolitis in soldiers returning from Iraq and Afghanistan. N Engl J Med 2011; 365: 222-230.

56 Phelan PD, Robertson CF, Olinsky A. The Melbourne Asthma Study: 1964-1999. J Allergy Clin immunol 2002; 109: 189-194.

57 Covar RA, Strunk R, Zeiger RS, et al. Predictors of remitting, periodic, and persistent childhood asthma. J Allergy Clin Immunol 2010; 125: 359-366.e353.

58 Miranda C, Busacker A, Balzar S, et al. Distinguishing severe asthma phenotypes: role of age at onset and eosinophilic inflammation. J Allergy Clin Immunol 2004; 113: 101-108.

59 Amelink M, de Groot JC, de Nijs SB, et al. Severe adult-onset asthma: a distinct phenotype. J Allergy Clin Immunol 2013; 132: 336-341.

60 Jenkins HA, Cherniack R, Szefler SJ, et al. A comparison of the clinical characteristics of children and adults with severe asthma. Chest 2003; 124: 1318-1324.

61 Bauer BA, Reed CE, Yunginger JW, et al. Incidence and outcomes of asthma in the elderly. A population-based study in Rochester, Minnesota. Chest 1997; 111: 303-310.

62 Shaaban R, Zureik M, Soussan D, et al. Rhinitis and onset of asthma: a longitudinal population-based study. Lancet 2008; 372: 1049-1057.

63 Barrecheguren M, Roman-Rodriguez M, Miravitlles M. Is a previous diagnosis of asthma a reliable criterion for asthma-COPD overlap syndrome in a patient with COPD? Int J Chron Obstruct Pulmon Dis 2015; 10: 1745-1752.

64 Kitaguchi Y, Komatsu Y, Fujimoto K, et al. Sputum eosinophilia can predict responsiveness to inhaled corticosteroid treatment in patients with overlap syndrome of COPD and asthma. Int J Chron Obstruct Pulmon Dis 2012; 7: 283-289.

65 Tamada T, Sugiura H, Takahashi T, et al. Biomarker-based detection of asthma-COPD overlap syndrome in COPD populations. Int J Chron Obstruct Pulmon Dis 2015; 10: 2169-2176.

66 Pavord ID, Lettis S, Locantore N, et al. Blood eosinophils and inhaled corticosteroid/long-acting beta-2 agonist efficacy in COPD. Thorax 2016; 71: 118-125.

67 Hasegawa K, Camargo CA Jr. Prevalence of blood eosinophilia in hospitalized patients with acute exacerbation of COPD. Respirology 2015; 21: 761-764.

68 Vedel-Krogh S, Nielsen SF, Lange P, et al. Blood eosinophils and exacerbations in COPD: the Copenhagen General Population Study. Am J Respir Crit Care Med 2016; 193: 965-974.

69 Pascoe S, Locantore N, Dransfield MT, et al. Blood eosinophil counts, exacerbations, and response to the addition of inhaled fluticasone furoate to vilanterol in patients with chronic obstructive pulmonary disease: a secondary analysis of data from two parallel randomised controlled trials. Lancet Respir Med 2015; 3: 435-442.

70 Aaron SD, Vandemheen KL, Maltais F, et al. TNFalpha antagonists for acute exacerbations of COPD: a randomised double-blind controlled trial. Thorax 2013; 68: 142-148.

71 Bafadhel M, Davies L, Calverley PM, et al. Blood eosinophil guided prednisolone therapy for exacerbations of COPD: a further analysis. Eur Respir J 2014; 44: 789-791.

72 Siddiqui SH, Guasconi A, Vestbo J, et al. Blood eosinophils: a biomarker of response to extrafine beclomethasone/ formoterol in chronic obstructive pulmonary disease. Am J Respir Crit Care Med 2015; 192: 523-525.

73 Wagener AH, de Nijs SB, Lutter R, et al. External validation of blood eosinophils, FE(NO) and serum periostin as surrogates for sputum eosinophils in asthma. Thorax 2015; 70: 115-120.

74 Park HY, Lee H, Koh WJ, et al. Association of blood eosinophils and plasma periostin with FEV1 response after 3-month inhaled corticosteroid and long-acting beta2-agonist treatment in stable COPD patients. Int J Chron Obstruct Pulmon Dis 2016; 11: 23-30.

75 Suissa S, Ernst P, Benayoun S, et al. Low-dose inhaled corticosteroids and the prevention of death from asthma N Engl J Med 2000; 343: 332-336.

76 Wurst KE, Kelly-Reif K, Bushnell GA, et al. Understanding asthma-chronic obstructive pulmonary disease overlap syndrome. Respir Med 2016; 110: 1-11.

77 Menezes AM, Montes de Oca M, Perez-Padilla R, et al. Increased risk of exacerbation and hospitalization in subjects with an overlap phenotype: COPD-asthma. Chest 2014; 145: 297-304.

78 van Boven JF, Roman-Rodriguez M, Palmer JF, et al. Comorbidome, pattern and impact of asthma-COPD overlap syndrome (ACOS) in real-life. Chest 2016; 149: 1011-1020.

79 Soriano JB, Davis KJ, Coleman B, et al. The proportional Venn diagram of obstructive lung disease: two approximations from the United States and the United Kingdom. Chest 2003; 124: 474-481.

80 Suzuki T, Tada Y, Kawata N, et al. Clinical, physiological, and radiological features of asthma-chronic obstructive pulmonary disease overlap syndrome. Int J Chron Obstruct Pulmon Dis 2015; 10: 947-954.

81 de Marco R, Marcon A, Rossi A, et al. Asthma, COPD and overlap syndrome: a longitudinal study in young European adults. Eur Respir J 2015; 46: 671-679.

82 Kim MA, Noh CS, Chang YJ, et al. Asthma and COPD overlap syndrome is associated with increased risk of hospitalisation. Int J Tuberc Lung Dis 2015; 19: 864-869.

83 Roche N, Reddel HK, Agusti A, et al. Integrating real-life studies in the global therapeutic research framework. Lancet Respir Med 2013; 1: e29-e30.

84 Christenson SA, Steiling K, van den Berge M, et al. Asthma-COPD overlap. Clinical relevance of genomic signatures of type 2 inflammation in chronic obstructive pulmonary disease. Am J Respir Crit Care Med 2015; 191: 758-766.

85 Hardin M, Cho M, McDonald ML, et al. The clinical and genetic features of COPD-asthma overlap syndrome. Eur Respir J 2014; 44: 341-350.

86 Miravitlles M, Alcazar B, Alvarez FJ, et al. What pulmonologists think about the asthma-COPD overlap syndrome. Int J Chron Obstruct Pulmon Dis 2015; 10: 1321-1330. 